\title{
Incidental thyroid nodules an ultrasound screening of the neck region: prevalence \& risk factors
}
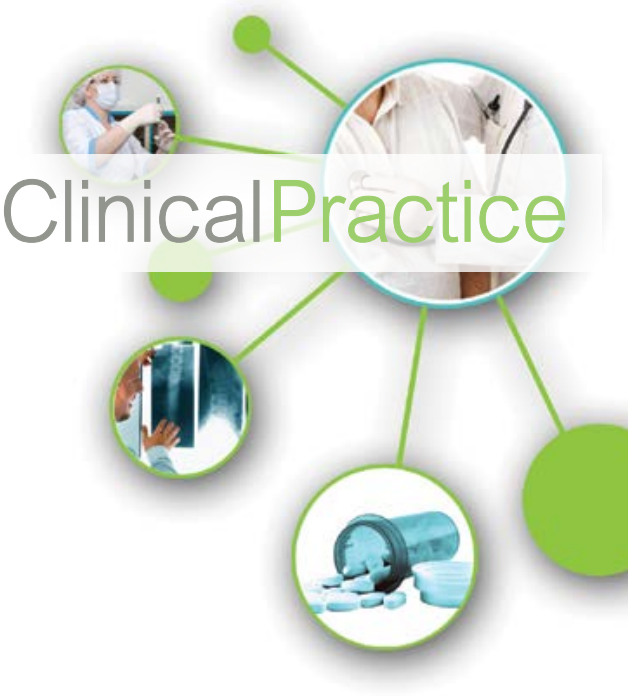

Objectives: The aim of this study is to determine the occurence of incidental thyroid nodules in patients undergoing routine neck ultrasound, and the presence of malignant thyroid nodules. This study also aims to evaluate the impact of age, sex, past medical history, habits and dietary intake as factors that can contribute to thyroid nodules.

Materials and methods: This study is retrospective. Past medical records and ultrasound reports of 150 patients were reviewed and all age groups and nationalities were included.

Results: Out of 150, incidental thyroid nodules were found in 32 patients (21.3\%). Incidence was higher in women with male to female ratio of $1: 3$ and the average age was 36.6 years. Nodules were solitary in 13 patients $(40.6 \%)$ and multiple in 19 (59.4\%). $53.1 \%$ of the nodules were located bilaterally while $46.9 \%$ were unilateral, occurring in only one of the thyroid lobes. The ultrasound reports revealed margins that are ill-defined in 4 nodules and well-defined in 11 nodules. $31 \%$ of the nodules were solid and only $15.6 \%$ presented coarse and dense calcifications. Based on the morphology, 10 nodules $(31.25 \%)$ were less than $5 \mathrm{~mm}$ in size, 13 nodules (40.6\%) had sizes ranging from 5 to $10 \mathrm{~mm}$, and 9 nodules (28.1\%) were dominant, measuring more than $10 \mathrm{~mm}$. However, no malignancy was reported.

Conclusions: Although their incidence is relatively low, incidental thyroid nodules are frequently present and must be evaluated carefully for any suspicious features like solid consistency, calcifications and hypoechogenecity.

\section{Keywords: incidental thyroid nodules, thyroid malignancy, thyroid cancer, ultrasound.}

\section{Introduction}

The thyroid is an endocrine gland, butterfly shaped. Its function is secretion of thyroid related hormones. Thyroid nodule is designated as an abnormal growth of thyroid cells which is found as a lump within the gland. Most of the nodules are benign in nature, but a small number do exhibit malignant tendencies. Given the prevalence, it is seen in about $4-7 \%$ of the global population. It is routinely found during palpation (4-8\%), ultrasound (10-41\%) and about $50 \%$ through autopsy. Ultra sound plays an important role in the detection of thyroid nodules, those which goes unrecognized during routine clinical examination.

The term Incidental thyroid nodules are coined due to the presence of newly seen nodules on imaging such as ultrasound, computed tomography, magnetic resonance imaging and the more advanced positron emission tomography.

Ultrasonography is the gold standard for study of thyroid nodules. It can detect small, multiple nodules and also isolate central or lateral neck lymphadenopathies.

It provides accurate clarity in dimensions. It also characterizes nodules if suggestive of malignancy by highlighting irregular margins, absence of halo, micro calcifications.

Characteristic features that could hint the prevalence of malignancy in a patient's history are previous head and neck irradiation, prevalence of rapid growth, dysphagia, and a family history of endocrine neoplasia or thyroid carcinoma.

\section{Thyroid Abnormalities}

Prevalence of thyroid abnormalities among females is more common. The most common are hyper and hypothyroidism, and thyroid enlargement, which is also termed goiter or thyroid nodule [1].

\section{Assessment of thyroid disease}

Thyroid function test or TFT gives
Sudhir Rama Varma*, Maher Al Shayeb*, Abed El Kaseh, Awad Ashekhi, Syed Kuduruthullah, Issmaeledin El Khader

Ajman University of Science and Technology College of Dentistry, UAE

*Author for correspondence:

mahshayeb@hotmail.com 
an indication of activity of thyroid gland. Measuring T3, T4 and TSH plays an active role. To determine the failure of production of thyroid hormones, TRH and TSH stimulation tests are carried out. Ultrasonography is vital to differentiate between active (hot) nodules and inactive (cold) nodules.

Advanced radiographic imaging like MRI (magnetic resonance imaging) and CT (computerized tomography) determines the extent of goitre. To determine nature of thyroid nodules, FNAC (fine needle aspiration cytology) is done. To detect autoimmune characteristics, thyroid antibodies are detected.

\section{Hormonal imbalance disorders}

Hyperthyroidism: Also termed Graves' disease, results in excessive thyroid hormone production. The clinical manifestation of hyperthyroidism includes weight loss, heat intolerance, palpitations, fatigue and irritability. Less commonly symptoms like tachycardia, osteoporosis, diarrhea, anxiety, muscle weakness, and alopecia can be seen. The firstline investigations are serum T3, T4 and TSH. In most patients, serum $\mathrm{T} 3$ and $\mathrm{T} 4$ are both elevated.

Hypothyroidism: Reduction in thyroid gland activity results in the said condition. symptoms include weight gain, hair loss, tiredness, in women heavy menstrual bleeding. Iodine deficiency causes $90 \%$ of the cases.

Thyroid enlargement: There are numerous causes that result in enlargement of the thyroid. Most common ones are solitary nodules, multinodular goitre or diffuse goitre.

Thyroid nodule is one of the most common endocrine diseases in the world. The term thyroid nodule refers to an abnormal growth of thyroid cells that forms a lump within the thyroid gland. Iodine is a substrate for thyroid hormone synthesis; therefore a deficient iodine uptake can trigger a reactive growth of thyroid gland tissue and lead to goiter and thyroid nodules [2]. Clinical assessment should address functional capacity of the thyroid. They are a common condition for referal. Based on histopathoilogical features, they are segregated as carcinomas, adenomas and lesions of hyperplastic origins. Studies of populations (such as Whickham in Northern England or Framingham in the US) have indicated that multinodular thyroids occur in around 5\% of female population $(10: 1)$. Autopsy studies have indicated a much higher incidence of nodular thyroid disease, indeed up to $50 \%$, with multinodular disease outnumbering single nodules by about 4 to 1. The incidence increases markedly in people over 50 years of age. It is much higher in areas of iodine deficiency indicating the importance of iodine in the etiology of nodularity [3]. When there is suspected malignancy, removal is the treatment of choice. In most cases, they are asymptomatic, with about $5-10 \%$ being malignant.

When the TFT (thyroid function test) is normal, the Ultra sound is employed for investigation.. Development in technology has increased the accuracy and sensitivity of many imaging modalities, resulting in the diagnosis of subclinical nodules in the adrenal, pituitary, and thyroid glands. Ultrasound imaging plays an important role in the detection of thyroid glands per se. About $5 \%$ of the adult population in western countries has a palpable thyroid nodule. The presence of malignancy can be attributed to US imaging features that highlight irregular margins, consistency of a solid nature, texture which is hypoechoic, absence of halo sign, presence of calcifications, and presence of cervical lymphadenopathy.

There are various limitations to do biopsy for every nodule found in US. The reasons being a small percentage of malignancy seen among nodules, cost factor, and patient anxiety. However, cytological examination is recommended for nodules over $1 \mathrm{~cm}$ in size. Individuals with a multiple nodules, termed multinodular goitre, have the same risk of malignancy as those with a solitary nodule.

\section{Dental Considerations}

Since there is a multidisciplinary treatment regime for treating patients with thyroid disease, The ATA (American thyroid association) guidelines for detection include that the patients have a serum TSH (Thyroid stimulating hormone) level evaluated starting at a age of 35 and every five years after that.

All elective dental dental treatment should be postponed till a complete medical profile has been done [4].

\section{Incidental thyroid nodules}

The ITN is one of the most common 
incidental findings on imaging studies that include the neck. Nodules which are not previously detected clinically but seen during routine imaging is termed as a ITN.

The detection of thyroid nodules has increased dramatically over the past years due to rapid advancements in imaging technology, especially CT, MRI, and ultrasound.

For diagnosing various thyroid diseases, US has become the imaging technique of choice.

\section{Benign thyroid nodule}

Echo pattern gets slightly distorted in benign nodules. After FNAC, the overall incidence is shown to be between $9.2 \%$ and $13 \%$. In patients with benign thyroid diseases, calcifications are rarer, being found most often in multinodular goiter [5].

\section{Malignant}

When nodules are measured to detect changes, both $\mathrm{AP}$ (antero posterior) and (TR) transvers diameters is assessed in axial planes. To be suggestive of malignancy, the AP diameter should be more than the TR diameter. The presence of hyperechoic foci of calcifiactions within the nodules also increases the chances of malignancy. Micro-calcifications present the most specific finding associated with malignancy $(-95 \%)$, mainly with papillary thyroid carcinoma. Some studies suggest that macrocalcifications (without associated microcalcifications) are not a risk factor for malignancy [6].

\section{Materials and Methods}

Approval from the ethical committee was granted from both Ajman univeristy and Ministry of Health in the UAE. The subjects included in this research were patients who had undergone neck ultrasound for medical evaluation for reasons other than thyroid evaluation. This involves patients who are referred to ultrasonography by the endocrinologist, maxillofacial surgeon, general surgeon, family physician or from ENT department and they are not aware of thyroid disease. Patients who have active thyroid diseases or disorders were excluded from the study. Ultrasound radiographic reports of 150 patients were retrospectively reviewed to determine the incidence of ITNs. Medical records were then reviewed to obtain demographic patient information, medical and family history.

\section{Statistical Analysis}

Using Microsoft Excel, information were organized and categorized in columns by age, gender, nationality, medical history, family history, and features of the thyroid nodules. With SPSS statistical software, statistical analyses were performed and data were demonstrated in charts and tables. However, due to the limited size of the sample, the $\mathrm{p}$-value and confidence intervals were not computed.

\section{Results}

Among 150 patients who underwent ultrasound imaging of the neck region, incidental thyroid nodules were found in 32 $(21.3 \%)$. Patients had a wide range of age. The youngest age reported was 8 and the oldest was 64 years old. The mean age was $36.3 \pm 11.5$ years old. Different ethnic backgrounds were recognized as shown on the chart to the right. Jordan has the highest incidence in our study with a percentage of $12.5 \%$, followed by India, UAE and Sudan, each having an incidence of $9.4 \%$ of the reported nodules. The female to male ratio is 3:1. Among the female patients, four had been diagnosed with hypothyroidism after the discovery of the thyroid nodules.

By reviewing medical records of the patients, medical history, family history and habits of smoking and alcohol consumption were obtained. The most commonly reported diseases in the family history are diabetes mellitus and hypertension. Nine patients suffer vitamin $\mathrm{D}$ deficiency and 5 are diagnosed with irondeficiency anemia. Vitamin B12 deficiency anemia, asthma, neuropathy, and dislipidemia were diagnosed in some patients as seen in TABLE 1. However, the habit of smoking was reported in two patients and alcohol consumption was reported from one patient only (TABLE 2).

On ultrasound reporting, 19 (59.4\%) patients had multiple nodules and 13 (40.6\%) patients had a solitary nodule. Among them, 15 had unilateral nodules located in one of the lobes, and 17 had nodules bilaterally.

The data on the margins of the nodules were available for 15 patients only. $34.4 \%$ of them had nodules with well-defined margins while illdefined margins were noted in $12.5 \%$. Ten of 
Table 1. Association between Thyroid nodules and various US features.

\begin{tabular}{|c|c|c|}
\hline Parameter & Patients with & Percentage \\
\hline & Nodules $(n=32)$ & \\
\hline \multicolumn{3}{|l|}{ Number of nodules: } \\
\hline Solitary nodule & 13 & 40.6 \\
\hline Multiple nodules & 19 & 59.4 \\
\hline \multicolumn{3}{|l|}{ Location of nodules: } \\
\hline Unilateral & 15 & 46.9 \\
\hline Bilateral & 17 & 53.1 \\
\hline \multicolumn{3}{|l|}{ Borders: } \\
\hline well-defined & 11 & 34.4 \\
\hline i|l-defined & 4 & 12.5 \\
\hline \multicolumn{3}{|l|}{ Echogenicity } \\
\hline Hypoechogenicity & 16 & 50 \\
\hline Hyperechogenicity & 4 & 12.5 \\
\hline \multicolumn{3}{|l|}{ Calcifications } \\
\hline dense/ coarse & 5 & 15.6 \\
\hline \multicolumn{3}{|l|}{ calcifications } \\
\hline \multicolumn{3}{|l|}{ Nodule Composition: } \\
\hline Solid & 10 & 31.3 \\
\hline Cystic & 2 & 6.25 \\
\hline \multicolumn{3}{|l|}{ Size of nodules: } \\
\hline$<5 \mathrm{~mm}$ & 10 & 31.3 \\
\hline Non-dominant (5-10mm) & 13 & 40.6 \\
\hline Dominant $(>10 m m)$ & 9 & 28.1 \\
\hline \multicolumn{3}{|c|}{ Symptoms of cervical lymph nodes involvement: } \\
\hline Enlargement: & 9 & 28.1 \\
\hline
\end{tabular}

Table 2. Association between patient history and thyroid nodules.

\begin{tabular}{|c|c|c|}
\hline Disease/habit & $\begin{array}{c}\text { Presence } \\
\text { in medical } \\
\text { history }\end{array}$ & $\begin{array}{c}\text { Presence } \\
\text { in Family } \\
\text { history }\end{array}$ \\
\hline $\begin{array}{c}\text { Diabetes } \\
\text { Mellitus }\end{array}$ & 1 & 4 \\
\hline $\begin{array}{c}\text { Hypertension } \\
\text { Vitamin D } \\
\text { deficiency }\end{array}$ & 0 & 3 \\
\hline $\begin{array}{c}\text { Iron-deficiency } \\
\text { anemia }\end{array}$ & 5 & O \\
\hline $\begin{array}{c}\text { Vitamin B12 } \\
\text { deficiency }\end{array}$ & 2 & 0 \\
\hline $\begin{array}{c}\text { anemia } \\
\text { asthma }\end{array}$ & 2 & $\mathrm{O}$ \\
\hline Neuropathy & 2 & $\mathrm{O}$ \\
\hline Dislipidemia & 2 & 1 \\
\hline smoking & 2 & 0 \\
\hline $\begin{array}{c}\text { Alcohol } \\
\text { consumption }\end{array}$ & 1 & $\mathrm{O}$ \\
\hline
\end{tabular}

the incidental nodules had solid composition and only two had cystic appearance. Analysis of echogenecity was available for 20 patients and

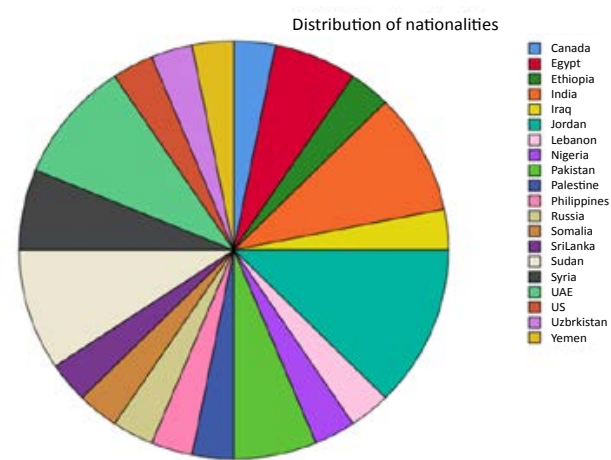

FIGURE 1. Distribution of nationalities

showed that 16 nodules $(50 \%)$ were hypoechoic and $4(12.5 \%)$ were hyperechoic. Some coarse calcifications were seen small and dense and were reported in 5 nodules (15.6\%).

The minimum size of the detected thyroid nodules was $1 \mathrm{~mm}$, while the maximum size was $42 \mathrm{~mm}$. The number of patients having nodules that measure less than $5 \mathrm{~mm}$ was 10 . Non-dominant nodules with sizes ranging from 5 to $10 \mathrm{~mm}$ were found in 13 patients, whereas dominant nodules with sizes larger than $10 \mathrm{~mm}$ 


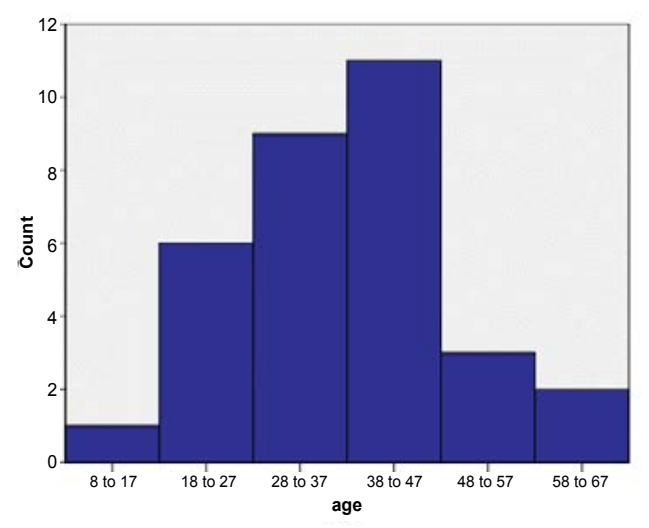

FIGURE 2. Age distribution of patients with thyroid nodules

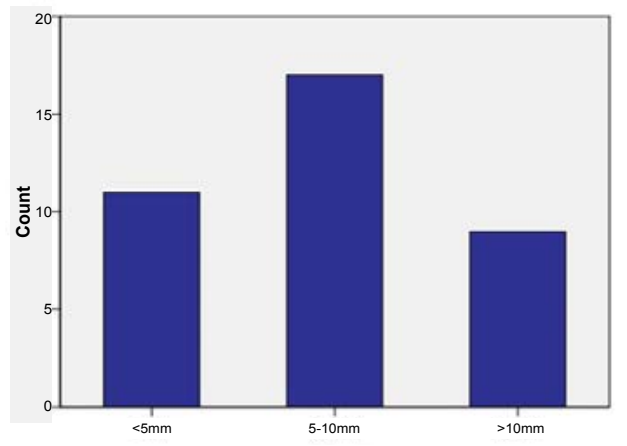

FIGURE 3. Size range of thyroid nodules

were seen in 9 patients. Lymph node assessment revealed enlargement of cervical lymph nodes in $9(28 \%)$ patients (FIGURES 1 and 2).

\section{Discussion}

The role of US in the detection of thyroid nodules has greatly increased, which normally goes unnoticed during routine clinical examination. As stated by the Incidental Thyroid Findings Committee that ITNs can be seen in 20 to $67 \%$ of ultrasound imaging, $25 \%$ of chest CT scans, and $18 \%$ of CT and MRI scans of the neck.

A study conducted by Rad M. et al. revealed an incidence of $19.6 \%$ of incidental thyroid nodules, which is very close to the incidence in our study (21.3\%). Min YK and his colleagues reported positive ITNs findings in $13.4 \%$ of Korean population. Many other studies indicated high prevalence of ITNs ranging from 3.9 up to $67 \%$.

Thyroid nodules seen in patients with a mean age is $36.3+11.5$ years, which is lesser than than a study conducted by Kamran et al. in Karachi 2014, in which the mean age was 39.25 \pm 14.8 years.
The least frequent age group in our study was from 8- 17 years old. This correlates with a statement in a study done by Singh et al. in 2011 that thyroid nodules occur less frequently in children than in adults.

Out of 32 patients, 24 were females (75\%) and 8 were males $(25 \%)$, which is in par with previous study done by Steele et al. in 2005 and the study done by Kamran et al. that indicated higher incidence in women, but in contrast to a study by Taheri et al. in an Iranian population in which $55.6 \%$ were males and $44.4 \%$ were females [7-9].

Reviewing of medical history of patients revealed that $28 \%$ suffer vitamin D deficiency. Although it is the most common disorder found among our patients, a study by Laney et al. stated that there is no significant association between vitamin D levels and thyroid nodules [10]. Even though anemia was reported in $21.9 \%$ of our patients, we did not find a study that correlate between anemia and thyroid nodules.

Based on ultrasound features analysis, our results indicate $59.4 \%$ of the patients had multiple nodules while $40.6 \%$ had single nodules. This corresponds to the results of an Italian study by Papini et al. in 2008 in which solitary nodules were found in $48.5 \%$ and multiple nodules in $51.5 \%$. However, a slight difference was found compared to the study done by Kamran et al. where nodules were solitary in 55\% and multiple in $45 \%$.

Taheri et al. observed unilateral nodules in $51.9 \%$ of and bilateral nodules in $48.1 \%$ of patients. Kamran et al. observed unilateral presence in $61 \%$ and presence in more than one location in $39 \%$ of patients. Both of these observations conflict with our results of detecting unilateral nodules in $46.2 \%$ of patients and multiple nodules in $53.1 \%$.

Out of 15 patients, eleven had well-defined margins while ill-defined margins were noted in four patients. According to a study performed by Kakkos et al., nodules that lost their smooth border are considered suspicious nodules and need further investigations to confirm the diagnosis [5]. Kwak and his colleagues conducted a study in 2011 on ultrasound features of nodules. They stated that nodules that appear hypoechoic are suggestive of a malignant nodule. In our study, $50 \%$ of patients had hypoechoic 
nodule while $12.5 \%$ had hyperechoic nodules. Our result was consistent with the result of Rad and his partners' study where they found that $32 \%$ of nodules were hypoechoic and $16 \%$ were hyperechoic [11]. Calcification (denes/ course) was a positive finding in the ultrasound of 5 patients. Course calcification can be seen in malignant nodules as stated by Kwak and his colleagues in 2011 .

Among our patients, ten (31.25\%) were reported to have solid nodules whereas two $(6.25 \%)$ of them were having cystic nodules. In contrast to our result, Moifo et al. cystic nodules were present in $49.4 \%$ and nodules of solid features were $33.6 \%$. To diagnose a nodule as benign, the nodules would appear cystic and also contain colloids, as such it does not require investigations with FNA (fine needle aspiration) [12-15]. According to size (FIGURE 3) 31.25\% were $<5 \mathrm{~mm}, 40.6 \%$ ranged from 5 to $10 \mathrm{~mm}$, and $28.1 \%$ were dominant measuring $>10 \mathrm{~mm}$. Moifo et al. concluded that the larger the size of the needle, the potential for it to become malignant increases, which seconds the need for a cytological examination, wherein, if the size is more than 10 , it needs examination and less than 5 does not warrant. Therefore, nine of our patients who had dominant nodules should be referred for further investigation. Lymph node assessment revealed enlargement of cervical lymph nodes in $9(28 \%)$ patients [16-30].

\section{Conclusions}

One of the limitations of our study was the limited size of the sample. Another limitation is that follow-up data and further investigations were not available for our study. Given the separate findings including that the incidence of ITNs is $21.3 \%$ with more than $25 \%$ being dominant nodules, women being involved by $75 \%$, dominant nodules being detected in $28 \%$, solid composition of $31 \%$ of nodules, and $28 \%$ of patients having lymph node involvement, we recommend further investigations for these patients due to suspicious findings. However, ethnic backgrounds, medical history and habits reported in our data do not have any significant effect on the presence of thyroid nodules, as they are not possible risk factors. 


\section{REFERENCES}

Walker BR, Colledge NR, Ralston SH, Pendman ID. Davidson's principles \& practice of medicine 22nd edition. United States: Churchill Livingstone (2014).

Guth S, Theune U, Aberle J, Galach A, Bamberger CM. Very high prevalence of thyroid nodules detected by high frequency $(13 \mathrm{MHz})$ ultrasound examination. EUR. J. CLIN. INVEST. 39 (8), 699-706 (2009).

Whitehead SA, Nussey SS. Endocrinology: an integrated approach. United Kingdom: BIOS Scientific Publishers (2013).

Pinto A, Glick M. Management of patients with thyroid disease: Oral health considerations. J. Am. Dent. Assoc. 133(7), 849-858 (2002).

Kakkos SK, Scopa CD, Chalmoukis AK, et al. Relative Risk of Cancer in Sonographically Detected Thyroid Nodules with Calcifications. J. Clin. Ultrasound. 28(7), 347-352 (2000).

Kwak JY, Han KH, Yoon JH, et al. Thyroid imaging reporting and data system for us features of nodules: A step in establishing better stratification of cancer risk. Radiology. 260, 892-899 (2011).

Steele SR, Martin MJ, Mullenix PS, Azarow KS, Andersen CA. The Significance of Incidental Thyroid Abnormalities Identified During Carotid Duplex Ultrasonography. Arch. Surg. 140, 981-985 (2005).

Kamran M, Hassan N, Ali M, et al. Frequency of thyroid incidentalomas in Karachi population. Pak. J. Med. Sci. 30(4), 793-797 (2014).

Taheri MS, Hemadi H, Haghighatkhah HR, et al. Prevalence of Incidental Thyroid Nodules Diagnosed by Ultrasound in an Iranian Population. Iran J. Radiol. 5(1), 19-23 (2008).

Laney N, Meza J, Lyden E, et al. The prevalence of vitamin $\mathrm{D}$ deficiency is similar between thyroid nodule and thyroid cancer. Int. J. Endocrinol. 10(2), 13-20 (2010).

Rad MP, Zakavi SR, Layegh P, Khooei
A, Bahadori A. Incidental Thyroid Abnormalities on Carotid Color Doppler Ultrasound: Frequency and Clinical Significance. J. Clin. Ultrasound. 23, 2528 (2015).

Moifo B, Tapouh JR, Fomekong SD, Djomou F, Wankie EM. Ultrasonographic prevalence and characteristics of nonpalpable thyroid incidentalomas in a hospital-based population in a subSaharan country. BMC Med. imaging. 17(1), 21 (2017).

Marieb EN, Hoehn KN. Human anatomy \& physiology 9th edition. United States: Pearson (2014).

Walker BR, Colledge NR, Ralston SH, Pendman ID. Davidson's principles \& practice of medicine 22nd edition. United States: Churchill Livingstone (2014).

Yousem DV, Huang T, Loevner LA, Langlotz CP. Clinical and Economic Impact of Incidental Thyroid Lesions Found with CT and MR. Am. J. Neuroradiol. 18, 1423-1428 (1997).

Papini E, Guglielmi R, Bianchini A, et al. Risk of Malignancy in Nonpalpable Thyroid Nodules: Predictive Value of Ultrasound and Color-Doppler Features. Int. J. Clin. Endocrinol. Metab. 87(5), 1941-1946 (2002).

Xie1 C, Cox P, Taylor N, LaPorte S. Ultrasonography of thyroid nodules: a pictorial review. Insights Imaging. 7, 7786 (2016).

Carroll BA. Asymptomatic Thyroid Nodules: incidental sonographic detection. Am. J. Roentgenol. 133, 499501 (1982).

Lee JH, Jeong SY, Kim YH. Clinical significance of incidental thyroid nodules identified on low-dose CT for lung cancer screening. Multidiscip. Respir. Med. 8, 56 (2013).

Shetty SK, Maher MM, Hahn PF, et al. Significance of Incidental Thyroid Lesions Detected on CT: Correlation among CT, Sonography, and Pathology. Am. J. Roentgenol. 187, 1349-1356 (2006).

Scherer K, Means S, Chijioke C, Karmin P, Panda M. Incidence of Incidental Thyroid Nodules on Computed Tomography (CT) Scan of the Chest Performed for Reasons Other than Thyroid Disease. Int. J. Clin. Med. 2, 264268 (2011).

Park JY, Lee KH, Cho SG, et al. Incidental thyroid nodules on thoracic contrast-enhanced computed tomography in clinical practice during a 10 -year period: Characteristics, clinical outcomes, and factors contributing to further evaluation. Medicine. 96, 11 (2017).

Ahmed S, Horton KM, Jeffrey RB, Sheth S, Fishman EK. Incidental Thyroid Nodules on Chest CT: Review of the Literature and Management Suggestions. Am. J. Roentgenol. 195, 1066-1071 (2010).

Hoang JK, Langer JE, Middleton WD, et al. Managing Incidental Thyroid Nodules Detected on Imaging: White Paper of the ACR Incidental Thyroid Findings Committee. J. Am. Coll. Radiol. 12(2), 143-150 (2014).

Kang HW, No JH, Chung JH, et al. Prevalence, Clinical and Ultrasonographic Characteristics of Thyroid Incidentalomas. Thyroid. 14(1), 29-33 (2004).

Ahmed S, Johnson PT, Horton KM, et al. Prevalence of unsuspected thyroid nodules in adults on contrast enhanced 16- and 64-MDCT of the chest. World J. Radiol. 4(7), 311-317 (2012).

Tan G, Gharib H. Thyroid incidentalomas: management approaches to nonpalpable nodules discovered incidentally on thyroid imaging. Ann. Intern. Med. 126(3), 226-231 (1997).

Ezzat $S$, Sarti DA, Cain DR, Braunstein GD. Thyroid incidentalomas: prevalence by palpation and ultrasonography. Ann. Intern. Med. 154(16), 1838-1840 (1994).

Yoon DY, Chang SK, Choi $\mathrm{CH}$, et al. The prevalence and significance of incidental thyroid nodules identified on computed tomography. J. Comput. Assist. Tomogr. 32(5), 810-815 (2008).

Garden J, Bradbury A, Forsythe J, Parks RW. Principles and Practice of Surgery 6th Edition. United States: Churchill Livingstone (2012). 